\title{
8
}
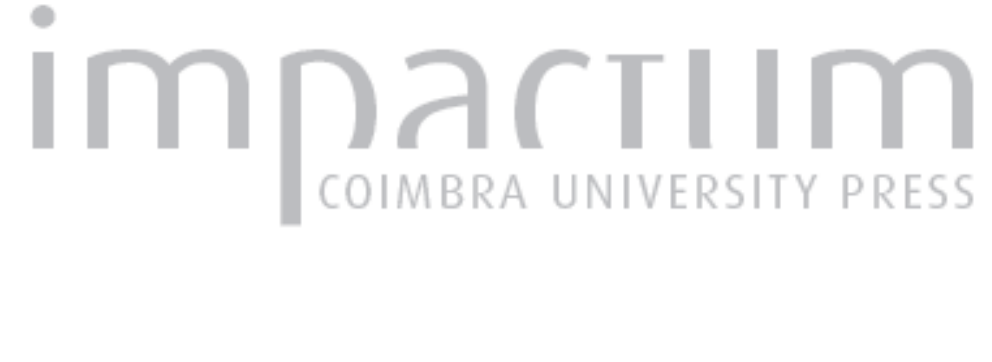

\section{Turismo, saúde e bem-estar: um mar de oportunidades no Município de Sines}

Autor(es): $\quad$ Brito, Mónica Belchior Morais de

Publicado por: Imprensa da Universidade de Coimbra

URL persistente:

URI:http://hdl.handle.net/10316.2/38314

DOI:

DOI:http://dx.doi.org/10.14195/0871-1623_34_4

Accessed : $\quad$ 26-Apr-2023 01:58:33

A navegação consulta e descarregamento dos títulos inseridos nas Bibliotecas Digitais UC Digitalis, UC Pombalina e UC Impactum, pressupõem a aceitação plena e sem reservas dos Termos e Condições de Uso destas Bibliotecas Digitais, disponíveis em https://digitalis.uc.pt/pt-pt/termos.

Conforme exposto nos referidos Termos e Condições de Uso, o descarregamento de títulos de acesso restrito requer uma licença válida de autorização devendo o utilizador aceder ao(s) documento(s) a partir de um endereço de IP da instituição detentora da supramencionada licença.

Ao utilizador é apenas permitido o descarregamento para uso pessoal, pelo que o emprego do(s) título(s) descarregado(s) para outro fim, designadamente comercial, carece de autorização do respetivo autor ou editor da obra.

Na medida em que todas as obras da UC Digitalis se encontram protegidas pelo Código do Direito de Autor e Direitos Conexos e demais legislação aplicável, toda a cópia, parcial ou total, deste documento, nos casos em que é legalmente admitida, deverá conter ou fazer-se acompanhar por este aviso.

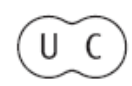




\title{
Turismo, saúde e bem-estar: um mar de oportunidades no Município de Sines Tourism, health and wellness: a sea of opportunities in the city of Sines
}

\author{
Mónica Belchior Morais de Brito \\ Departamento Geografia e Turismo. Faculdade Letras. Universidade Coimbra \\ CEGOT- Centro de Estudos de Geografia e Ordenamento do Território \\ monicabrito71@gmail.com
}

\section{Resumo:}

A atual perceção de saúde, de acordo com o conceito da OMS, constitui uma oportunidade para o desenvolvimento dos territórios, nomeadamente na perspetiva do Turismo, podendo estimular a emergência de produtos turísticos, como o Turismo de Saúde e Bem-estar, que em complementaridade com outros, contribuem para a sua reinvenção e diferenciação e, consequentemente para a sua competitividade. Por outro lado, a aposta na produtização dos recursos naturais, nomeadamente do mar, em abordagens distintas das convencionais, pode alavancar o desenvolvimento turístico sustentável dos destinos, na medida em que fomentam a diversificação da oferta e aumentam a sua atratividade. No âmbito de um estudo realizado sobre o Município de Sines, com o objetivo de definir políticas e práticas para o desenvolvimento turístico deste território, este produto turístico surge, em complementaridade com outros, como uma via de sustentabilidade, associado em particular à talassoterapia, uma prática milenar revisitada na pós-modernidade, com capacidade para alavancar uma oferta diferenciada e competitiva com caraterísticas dissuasoras da sazonalidade e potenciadoras do aumento do tempo de estada dos visitantes.

Palavras-chave: Turismo. Saúde. Bem-estar. Mar. Talassoterapia. Sustentabilidade

\section{Abstract:}

The current health perception, according to the WHO definition, is an opportunity for the development of territories, particularly in the tourism perspective, can encourage the emergence of tourism products, such as the Tourism of Health and Welfare, which complementarity with others, contribute to its reinvent and differentiation and thus to their competitiveness. On the other hand, the focus on productization of natural resources, including sea, in different approaches of conventional, can leverage sustainable tourism development of destinations, in that foster diversification of supply and increase their attractiveness. As part of a study on the municipality of Sines, in order to define policies and practices for tourism development of this territory, this tourism product comes in complementarity with others, as a way of sustainability, associated in particular the Thalassotherapy one ancient practice revisited in post-modernity, able to leverage a differentiated and competitive offer with deterrent characteristics of seasonality and potentiate the increase in visitor stay time.

Keywords: Tourism. Health. Wellness. Thalassotherapy. Sustainability

\section{Introdução}

A perceção que temos da relação entre o turismo e o mar é quase sempre convencional e mesmo quando mais arrojada quase sempre se cinge à prática desportiva, seja por motivos de lazer ou de competição. No entanto, num contexto em que crescentemente se fala da Economia do Mar, num país que se pauta por uma Estratégia Nacional para o Mar, esta será uma perspetiva redutora face à enormidade de oportunidades que o mar encerra quando o turismo entra na equação.

De acordo com a Estratégia Nacional para o Mar 2013-2020, o “Crescimento Azul”, comunicação apresentada em 2012 pela União Europeia, identifi- ca cinco domínios estratégicos de intervenção preferencial, designadamente a energia azul, a aquicultura, o turismo marítimo, costeiro e de cruzeiros, os recursos minerais marinhos e a biotecnologia azul (DGPM, 2015). No entanto, no nosso entender a rentabilização turística do mar não se esgota nos produtos apontados, existindo zonas de confluência entre os vários domínios que podem redundar em oportunidades para o turismo, potenciando o perfil da nova procura, motivada por experiências diferenciadas e diferenciadoras que vão ao encontro do perfil do "novo turista". Neste campo, situamos as potencialidades dos recursos marinhos na promoção da saúde e do bem-estar, ligados nomeadamente a práticas como a talassoterapia, uma prática milenar que põe as propriedades bioquímicas do mar ao 
serviço da prevenção e do tratamento e que se objeto de produtização poderá constituir uma alavanca para o desenvolvimento turístico dos territórios costeiros.

Neste contexto, surge o Turismo de Saúde e Bem-Estar cujo modelo decorre da própria definição de saúde avançada pela Organização Mundial de Saúde (OMS), que a define como um estado de completo bem-estar físico, mental e social, e não simplesmente a ausência de doença. Esta definição pressupõe que as iniciativas de promoção de saúde não se devem dirigir apenas ao controlo de sintomas, diminuição da mortalidade ou aumento da esperança de vida mas também ao bem-estar e à qualidade de vida. Um conceito complexo e completo que, apesar de datar de 1948, reflete os valores da pós-modernidade, sendo crescentemente objeto de forte perseguição individual e societal. Na realidade, a interiorização deste conceito e a sua materialização em valores, atitudes e comportamentos, culmina atualmente num culto do corpo e da mente indutor da procura de novas vias para o bem-estar e para a saúde. Longe da época em que a atuação se restringia somente à profilaxia e ao tratamento, nos países desenvolvidos adopta-se hoje uma postura pró-ativa em que os esforços visam igualmente a prevenção.

Esta relação entre o mar e o turismo, distinta da convencional, apanágio apenas de alguns territórios, encontra em Sines um cenário propício ao seu desenvolvimento, pois desde as reminiscências do passado às oportunidades do presente, o Turismo de Saúde e Bem-estar, a desenvolver-se, encerra perspetivas de procura e de sucesso. A análise deste território, nomeadamente através dos olhos dos seus visitantes e dos atores que intervém no planeamento e desenvolvimento turístico, aos quais foram realizados inquéritos por questionário e por entrevista, respetivamente, permite concluir que existe uma situação de partida favorável à implementação da talassoterapia e à sua produtização turística, ainda que na consciência de que na atualidade existe uma completa ausência de oferta neste domínio e que há um caminho a percorrer, ao nível do planeamento e da ação, até se considerarem reunidas as condições para a sua emergência e afirmação. A investigação que desenvolvemos permitiu, a partir da leitura e interpretação diagnóstico, definir um conjunto de objetivos e de estratégias que pretendem dar um contributo para que, em diferentes horizontes temporais, Sines se transforme num território de Turismo de Saúde e Bem-estar a partir de um dos seus principais recursos, o Mar.

\section{Entre a teoria e a prática - uma abordagem sumária ao Turismo de Saúde e Bem-Estar}

A perceção do Turismo de Saúde e do Turismo de Bem-estar, como práticas ligadas à pós-modernidade, é negada pela sua existência milenar, embora regida por padrões distintos e em épocas em que o turismo dava os primeiros passos. Na Grécia antiga, os peregrinos e os pacientes deslocavam-se da zona do mediterrâneo para o santuário de Asklepios (Deus da Saúde), em Epidaurus, simultaneamente um sanatório e uma escola de medicina. Também é à Grécia que o turismo deve a criação das principais estâncias hidrominerais. Poetas famosos, como Homero e Píndaro, louvaram as propriedades das águas, e foi para responder aos que procuravam a cura pelas águas, que se construíram as primeiras hospedarias e as "residências de verão" da aristocracia. No apogeu do Império Romano, os aristocratas de Roma procuravam evadir-se das cidades sobrelotadas, deslocando-se para as cidades litorais para banhos medicinais. A talassoterapia data de 500 anos a.C. e dessa época também datam os primeiros SPAs registados na história da humanidade. Nas termas, os romanos concretizavam o ideal filosófico: "Mens sana in corpore sano", dado que estas estâncias permitiam purificar o corpo nas salas de banhos e através de exercícios físicos, dispondo de bibliotecas e recintos destinados a reuniões, leituras e debates (IGNARRA, 2003).

No séc. XVIII apenas os europeus mais abastados tinham acesso aos serviços de saúde e bem-estar, mas actualmente o custo relativamente baixo das viagens democratizou o turismo, e no caso particular dos dois produtos turísticos em análise, as mudanças de mentalidade, a adoção de novos valores sobre o corpo, o espírito, a saúde e a beleza, estão a contribuir para que se transformem numa indústria multimilionária, onde o papel desempenhado pelo marketing e pelas novas tecnologias se tem revelado fundamental para sucesso e para a afirmação à escala global (IGNARRA, 2003).

A estas práticas associa-se uma confusão conceptual e terminológica, que integra saúde e bem- estar num mesmo produto, quando estamos perante dois produtos turísticos procurados por motivos diferentes e direccionados para fins igualmente distintos. O Turismo de Saúde, apesar da existência de uma multiplicidade de conceitos, pode ser definido como a deslocação das pessoas do seu local de residência por razões de saúde (ROSS, 2001). A afirmação deste produto turístico está directamente relacionada com os seguintes factores:

- O envelhecimento da população: a geração resultante do baby boom do pós II Guerra Mundial tem atualmente uma situação face ao emprego, decorrente da idade, e um rendimento disponível que the confere uma forte propensão para viajar em busca da reposição da saúde. Pelas suas características, são potenciais turistas interessados sobretudo na localização, nas caraterísticas do destino, na privacidade e na qualidade, em detrimento do preço.

- As mudanças no estilo de vida: os estilos de vida desta quota de mercado significam uma procura crescente dos SPAs, de health clubs, e de clínicas especializadas para tratamentos específicos, no sentido da recuperação da saúde.

- O turismo alternativo: atualmente os turistas procuram novas experiências turísticas, em que tenham contacto com coisas novas e diferentes.

- Características dos Sistemas de Saúde: longas listas de espera, custos elevados, falhas nos seguros, 
entre outros fatores negativos, estimularam a ida para o estrangeiro à procura de cuidados de saúde. Quando os sistemas nacionais não conseguem providenciar adequadamente e/ou atempadamente soluções para as necessidades da população, esta procura no exterior a resposta para essas mesmas necessidades. Esta atitude é entendida como uma via para desenvolver a economia dos países recetores e os problemas do sistema nacional de saúde dos países emissores (BORMAN, 2004).

O bem-estar é um produto turístico extremamente presente no turismo europeu, em que a qualidade, principal determinante da sua competitividade, deve constituir o objetivo do planeamento, das estratégias e da ação. A especialização neste tipo de oferta pressupõe um conhecimento aprofundado na área da saúde, a disponibilização de cuidados individualizados e um vasto leque de programas culturais e de relaxamento. No entanto, o mesmo estabelecimento pode oferecer cuidados de saúde e cuidados de bem-estar, dois segmentos que têm que ser encarados separadamente aquando da definição da estratégia de marketing, na medida em que se os serviços de bem-estar são procurados por pessoas saudáveis numa perspectiva de prevenção, enquanto os cuidados de saúde, cujo principal objectivo é o tratamento da doença, são procurados por turistas que desejam reaver a sua saúde.

0 conceito de bem-estar foi desenvolvido por Dunn (1959), quando escreveu pela primeira vez sobre um estado especial de saúde que se traduzia num bem-estar total do homem, enquanto ser constituído por corpo e mente e dependente do ambiente circundante. Trata-se de um conceito que foi evoluindo ao longo do tempo, trabalhado por inúmeros autores. Travis (1984) salientou o aspecto dinâmico do bem-estar, definindo-o como um estado, uma atitude e um processo de evolução, e não como um processo estático, e considerando a existência de diversos graus de bem-estar tal como de doença. Por outro lado, a análise e interpretação da definição avançada por Ardell (1986), permite-nos entender o bem-estar como um estado de saúde resultante da harmonia entre o corpo e a mente, alcançada através da auto-responsabilidade, dos cuidados com a beleza e com a condição física, de uma dieta saudável, do relaxamento e meditação (necessários para combater o stress), da actividade mental e educação, da sensibilidade ambiental e dos contactos sociais. Para além destas, existem inúmeras outras definições de bem-estar, tendo em comum alguns aspetos: a importância do estilo de vida, a responsabilidade sobre a própria saúde, as múltiplas vias para a saúde, e o potencial para uma maior qualidade de vida.

o Turismo de Saúde é o somatório de todas as relações e fenómenos resultante da deslocação das pessoas com o objetivo de promover, estabilizar, e restaurar o bem-estar físico, mental e espiritual, utilizando para isso serviços de saúde localizados em sítios, onde não residem nem trabalham. Por seu lado, o Turismo de Bem-estar é o somatório de todas as relações e fenómenos resultantes da viagem e estada de pessoas motivadas pela preservação ou promoção da sua saúde, que permanecem em hotéis especializados, sujeitos a cuidados individuais prestados por profissionais qualificados para o efeito. Neste contexto, é requerido um pacote que integre preparação física, cuidados de beleza, dieta saudável, relaxamento e meditação, atividade mental e instrução (MUELLER e KAUFMANN, 2001).

As "férias saudáveis" podem ser proporcionadas por uma instituição de tratamento, contudo é necessário fazer uma clara distinção entre bem-estar e tratamento, sobretudo no ângulo da política de saúde. Do lado da procura, assume-se à partida que o bem-estar é somente perseguido por pessoas saudáveis, com um objectivo de prevenção. No entanto, tem que se estabelecer uma destrinça entre o bem-estar decorrente de um pacote de serviços (composto por preparação física, cuidados de saúde, dieta saudável, relaxamento e meditação, actividade mental e educação) e a prevenção da doença propriamente dita. Na realidade, os hóspedes que visam o bem-estar podem requerer serviços muito similares aos pretendidos pelos que procuram o tratamento, mas com a motivação de preservar ou de promover a saúde, e não de repor a saúde. Por conseguinte, entre o Turismo de Saúde e o Turismo de Bem-estar, mais do que os serviços pretendidos, é a motivação dos turistas que revela a existência de produtos turísticos distintos. No entanto, é extremamente complicado traçar a fronteira entre estes dois produtos turísticos, na medida em que os mesmos prestadores podem responder a ambas as motivações.

A Figura 1 representa esquematicamente a relação de proximidade entre o Turismo de Saúde e o Turismo de Bem-estar, evidenciando contudo, que para além dos denominadores comuns, existem pontos de divergência que afastam estes dois produtos turísticos.

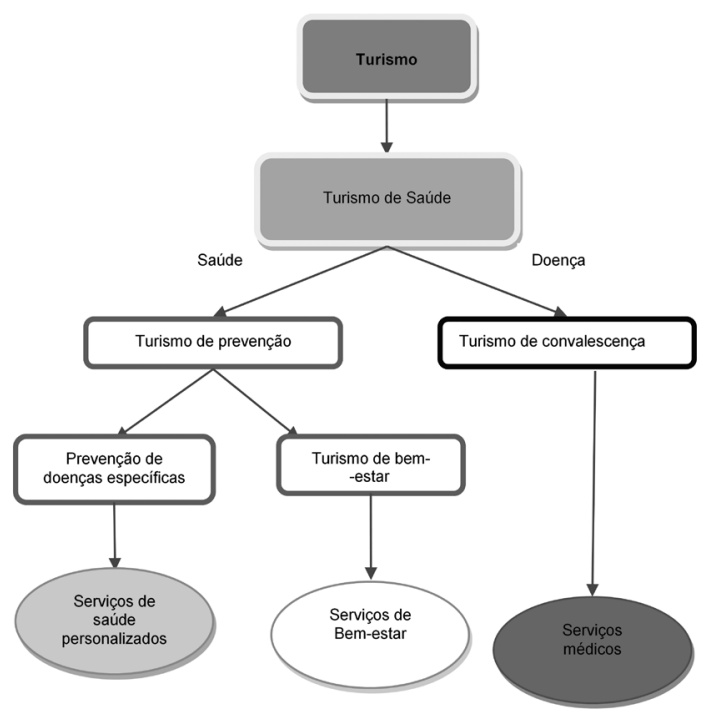

Figura 1

O Turismo de Saúde e de Bem-estar no âmbito da procura turística Fonte: MUELLER e KAUFMANN, 2001: 8 
A análise do mercado do Turismo de Bem-estar permite concluir que é imperativo uma demarcação clara entre o conceito de bem-estar e o de tratamento. O posicionamento no mercado profissional dos serviços de bem-estar só pode ser bem-sucedido se houver uma clara distinção entre estes e os direccionados para o tratamento de doenças. 0 processo de credibilização decorrente desta abordagem tornará mais atraente a cooperação entre o setor público e privado e tornará mais eficiente a estratégia promocional. Na realidade, para a estratégia de marketing é essencial que estes dois segmentos turísticos sejam separados, embora ambos os tipos de turistas possam ser hospedados no mesmo estabelecimento e ter acesso a serviços similares.

No entanto, nem todos os países reúnem condições para se afirmarem nestes campos, uma vez que como já salientámos existe uma trilogia essencial para o sucesso: preço, qualidade dos serviços de saúde e de bem-estar, e qualidade da experiência turística. Estas exigências transformam num desafio a aposta no seu desenvolvimento e pressupõem uma aliança entre o sector do turismo e da saúde num contexto de integração e articulação entre as políticas e as práticas de ambos os setores.

No caso particular de Portugal, como já foi anteriormente referido, o Plano Estratégico Nacional para o Turismo (PENT), para o horizonte 2013-2015, identifica como aposta, no âmbito dos dez produtos estratégicos "Qualificar e classificar a oferta de turismo de saúde, com vista ao desenvolvimento e crescimento deste produto de relevância estratégica para Portugal, nas componentes médica, termalismo, spa e talassoterapia, estimulando a estruturação e a promoção conjunta das valências médica e turística (MINISTÉRIO DA ECONOMIA E DO EMPREGO, 2013).

$A$ introdução deste produto, a quem são reconhecidas caraterísticas compatíveis com um modelo de desenvolvimento turístico sustentável, deve-se ao facto do país possuir um conjunto de recursos cuja rentabilização the pode conferir uma considerável competitividade neste segmento do mercado turístico, em que se verifica uma procura crescente. Neste momento, este setor representa três milhões de viagens internacionais por ano na Europa, sendo a procura primária de viagens internacionais de Saúde e Bem-Estar, aquela para a qual esse é o principal motivo da viagem, composta por 3 milhões de viagens de uma ou mais noites de duração. Este volume representa aproximadamente $1,2 \%$ do total de viagens de lazer realizadas pelos europeus, prevendo-se um crescimento da procura anual a um ritmo de $5-10 \%$, com a particularidade de que o gasto médio por pessoa é, regra geral, superior ao dos restantes sectores, devido ao gasto em tratamentos terapêuticos e similares, situando-se entre os $100 €$ e os $400 €$, sem transporte incluído (THR, 2006).

Embora no PENT 2013-2015, aquando da análise das regiões na perspetiva dos produtos estratégicos, o Turismo de Saúde seja classificado como "Sem Expressão" no Alentejo, consideramos que o Alentejo Litoral, e o Município de Sines em particular, podem tornar-se um destino de saúde e bem-estar, destacando-se nomeadamente ao nível da talassoterapia, dos tratamentos a partir da água do mar, mas não ignorando outro tipo de tratamentos como por exemplo: (1) Anti-stress, beleza, adelgaçante, anti-tabaco, entre outros (2) Banhos: hidromassagem, talassoterapia (3) Massagens: distensão, drenagem linfática, reflexologia, shiatsu, tailandês, entre outros. Nesta dimensão existem inúmeros tratamentos e programas que pelas suas caraterísticas podem ser compatíveis com as condições bioclimáticas deste território. 0 consumidor de viagens de wellness procura, além de tratamentos das mais variadas tipologias, um cenário que proporcione uma sensação de comodidade, bem- estar e descontração, com o objetivo de obter a máxima satisfação na sua viagem, sendo que o Alentejo Litoral, e também o Município de Sines, possui condições naturais e paisagísticas que vão ao encontro da exigência da procura destes tipos de produtos, apenas necessitando de the aliar uma oferta sofisticada, recursos humanos especializados, alojamentos de qualidade e harmoniosos com a natureza, bons acessos, informação clara e em diversos idiomas, para reunir condições competitivas face à restante oferta nacional e internacional (THR, 2006).

Em suma, o Turismo de Saúde e de Bem-estar constitui uma tendência internacional manifestada por consumidores cada vez mais preocupados com a sua saúde física e mental, e que procuram aliar a melhoria do seu bem-estar às experiências turísticas que vivenciam. Este tipo de consumidor procura parecer e sentir-se melhor, perder peso, retardar os efeitos do envelhecimento, aliviar a dor ou o desconforto, controlar o stress, ou fazer um suplemento natural de vitaminas e minerais com o objectivo de melhorar a saúde. Respondendo a esta procura e contribuindo para a criação de novas necessidades, os resorts e os hotéis aumentam a sua oferta de serviços de saúde e bem-estar, oferecendo programas estruturados específicos, para além dos seus serviços convencionais. Este comportamento simultaneamente reativo e pró-ativo, aumenta a capacidade de atração das unidades hoteleiras e dos destinos turísticos, diversificando a oferta e aumentando os lucros do processo turístico.

Para além da questão conceptual, a prestação de serviços de qualidade revela-se vital como resposta à competição internacional e às elevadas expetativas dos turistas. As infraestruturas vocacionadas para a promoção do bem-estar, e uma equipa especializada que assista individualmente os turistas, constituem pilares fundamentais do conceito internacional de qualidade no âmbito do Turismo de Bem- estar (MUELLER e KAUFMANN, 2001).

No âmbito destes produtos, a qualidade, principal determinante da sua competitividade, deve constituir o objetivo do planeamento, das estratégias e da ação. A especialização neste tipo de oferta pressupõe um conhecimento aprofundado na área da saúde, a disponibilização de cuidados individualizados e um vasto leque de programas culturais e de relaxamento, diversificando e sofisticando a oferta, e aumentando as mais-valias do processo turístico. 


\section{A metodologia}

A informação que suporta o presente artigo foi recolhida no âmbito da investigação realizada pela autora aquando da elaboração da sua dissertação de Doutoramento, com o objetivo primordial de propor um conjunto de políticas e práticas conducentes ao desenvolvimento turístico sustentável do Município de Sines. O Turismo de Saúde e Bem-Estar surge como um dos produtos que, perante os antecedentes e os recursos existentes, se pode inserir no modelo a preconizar.

A informação não disponível foi recolhida através da realização de inquérito por entrevistas e por questionário. As entrevistas semi-diretivas foram realizadas a um painel de stakeholders diretamente ligados ao planeamento e desenvolvimento turístico, discriminado no Quadro I, durante o $3^{\circ}$ trimestre de 2011. A sua operacionalização foi norteada por duas grandes dimensões: o presente e o futuro, e segundo um guião semiestruturado subordinado aos seguintes temas: (1) Análise SWOT do sistema turístico no Município de Sines; (2) Conceptualização do desenvolvimento turístico no Município de Sines; (3) Definição de políticas e práticas conducentes ao desenvolvimento turístico sustentável no Município de Sines; (4) Identificação dos principais atores e dos papéis que devem assumir no âmbito do processo de planeamento e desenvolvimento turístico.

No que concerne ao questionário, o instrumento de coleta de informação foi aplicado aos visitantes do Município de Sines que visitaram os Postos de Turismo de Sines e do Porto Covo entre o dia 1 de Setembro de 2010 e o dia 31 de Agosto de 2011. A população-alvo é constituída por todos os visitantes desta unidade territorial, sendo que o questionário foi aplicado a uma amostra não probabilística acidental constituída por 208 indivíduos. Trata-se de uma amostra não probabilística na medida em que os elementos da população não possuem a mesma probabilidade de serem selecionados aquando da sua

Quadro I

Painel de Entrevistados constituição, sendo acidental porque a sua presença no grupo está relacionada com a sua presença num determinado local e num determinado momento, mais concretamente nos Postos de Turismo de Sines e de Porto Covo, no período temporal referido (FREIXO, 2009).

A aplicação definitiva do questionário foi antecedida pela realização de um pré-teste, em que foi aplicado o instrumento a 12 indivíduos, no mesmo contexto da aplicação definitiva, sendo que os resultados alcançados não revelaram necessidades de reformulação, por via da linguagem utilizada, nem de acréscimo de categorias de resposta, com vista ao aumento da exaustividade, o que levou à sua integração na amostra global.

Após o devido tratamento, análise de conteúdo das entrevistas e análise estatística dos questionários, a informação resultante, per si e na sua inter-relação, permitiu diagnosticar o presente e definir caminhos de futuro, genericamente sobre o sistema turístico do Município, e em particular sobre produtos turísticos considerados estratégicos, entre os quais se insere o Turismo de Saúde e Bem-estar.

\section{O território}

O Município de Sines situa-se entre a serra e o mar, tem na sua retaguarda as Serras de Grândola e do Cercal, faz fronteira, a poente, com o Oceano Atlântico e tem a Norte as lagoas da Sancha, Santo André e Melides. É um dos cinco pertencentes ao Alentejo Litoral, apresentando uma costa com $53 \mathrm{~km}$ e uma superfície de $203 \mathrm{~km}^{2}$, que compreende as freguesias de Sines e de Porto Covo, sendo o mais pequeno da NUT III a que pertence. Situa-se no centro da faixa costeira do Alentejo, $150 \mathrm{~km}$ a Sul de Lisboa e $80 \mathrm{~km}$ a Sul de Setúbal, a cujo distrito pertence. Confina a Norte e Este com o Município de Santiago do Cacém e a Sul com Município de Odemira.

\begin{tabular}{l|l|l}
\hline \multicolumn{1}{c|}{ Entidade } & \multicolumn{2}{c}{ Interlocutor } \\
\hline Entidade Regional de Turismo do Alentejo & António Ceia da Silva & Presidente \\
\hline $\begin{array}{l}\text { Pólo de Desenvolvimento Turístico do Litoral Alentejano } \\
\text { - Turismo do Alentejo Litoral }\end{array}$ & Carlos Silva & Vice-Presidente Executivo \\
\hline $\begin{array}{l}\text { Comissão de Coordenação e Desenvolvimento Regional } \\
\text { do Alentejo }\end{array}$ & Fátima Bacharel & $\begin{array}{l}\text { Diretora de Serviços de Ordenamento do Terri- } \\
\text { tório da CCDRA }\end{array}$ \\
\hline $\begin{array}{l}\text { Instituto de Conservação da Natureza e da Biodiversida- } \\
\text { de, IP - Parque Natural do Sudoeste Alentejano e Costa } \\
\text { Vicentina }\end{array}$ & José Paulo Fonseca & Supervisor \\
\hline $\begin{array}{l}\text { Câmara Municipal de Sines } \\
\text { Administração do Porto de Sines }\end{array}$ & Manuel Coelho Carvalho & Presidente \\
\cline { 2 - 3 } & Pedro Martins & $\begin{array}{l}\text { Chefe da Divisão de Planeamento, Ordenamen- } \\
\text { to do Território e Ambiente }\end{array}$ \\
\hline $\begin{array}{l}\text { Essuipa de Revisão do PDM do Município de Sines } \\
\text { Costa Alentejana }\end{array}$ & Lídia Sequeira & Presidente da Administração \\
\hline EmViagem - Agência de Viagens & Joaquim Parrinha & Representante \\
\hline
\end{tabular}

Fonte: Elaboração própria 
Numa outra perspetiva, há que evidenciar a sua localização entre o Oceano Atlântico e Espanha, entre a Área Metropolitana de Lisboa e o Algarve, uma posição privilegiada, nomeadamente no que toca às redes de infraestruturas e equipamentos. Há ainda que ponderar a ligação funcional portuária entre o Tejo, o Sado e Sines, complexo que poderá revelar-se de grande importância futura para a região. A sua localização geográfica e o seu posicionamento relativo têm-se constituído como factores de atração para inúmeros setores de atividade, conferindo a este Município um protagonismo crescente no contexto nacional e internacional.

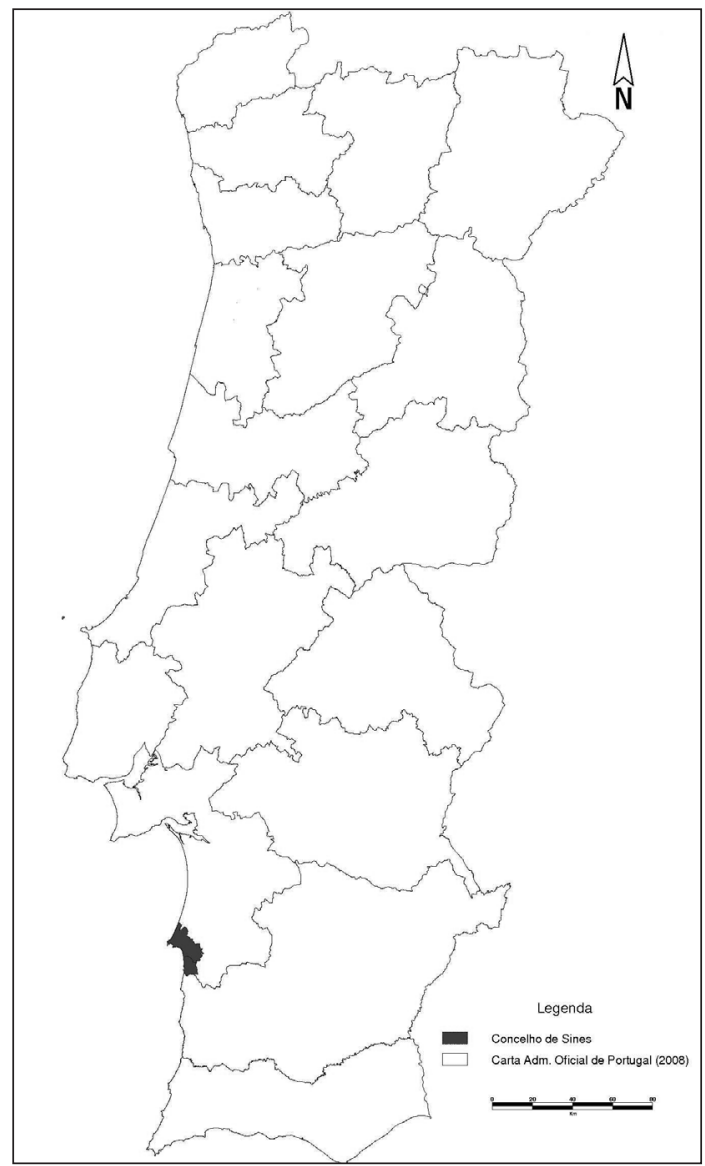

Figura 2

O Município de Sines representado no mapa de distritos Fonte: Núcleo SIG do Município de Sines, 2012

Outra importante caraterística deste Município, pelo estatuto que lhe confere, mas também pelo contributo que dá para a preservação das suas mais-valias naturais, é o facto de pertencer, parcialmente, ao Parque Natural do Sudoeste Alentejano e Costa Vicentina. Este território protegido, criado em 1995, situa-se entre a Ribeira da Junqueira, Santo Torpes (Município de Sines), e a praia da Boca de Rio (Município de Vila do Bispo), numa área de $75.000 \mathrm{ha}$, que entra pelo mar adentro $(2 \mathrm{~km})$, ao longo de $100 \mathrm{~km}$ da costa do Sudoeste de Portugal, albergando um valioso património natural e uma grande diversidade paisagística, pontuada por dunas e arribas.

Para além desta caracterização sumária, há ainda a evidencia, que este é um território que, pelas suas caraterísticas, pelos seus recursos e pela multiplicidade de atividades que alavancam o seu dinamismo económico, apresenta uma apetência natural para o desenvolvimento complementar de vários produtos turísticos, cujo estado de maturidade na atualidade é variável. Ainda que a presente abordagem seja centrada no Turismo de Saúde e Bem-estar, o Turismo Industrial e a Meeting Industry revelam-se igualmente viáveis, e o Turismo de Sol e Mar constitui uma referência e uma imagem de marca deste Município, desde a segunda metade do séc. XIX até à atualidade, embora hoje mais ligado à Freguesia de Porto Covo.

\section{Os antecedentes}

No passado, uma das atrações turísticas deste território eram os banhos quentes, que de acordo com a actual classificação dos produtos turísticos, se enquadrariam no Turismo de Saúde e Bem-estar. Não se sabe ao certo a data da inauguração desta estância termal, embora se saiba que constituía um pólo importante de atração de visitantes. De acordo com o relato de uma habitante: "Os banhos quentes eram uma casa grande e bonita. Á entrada existia um aparelho muito bonito que tocava música, no interior do edifício existiam alguns quartos, mais propriamente umas separações, e cada uma delas tinha uma banheira de pedra forrada, uma cadeira e um cabide para os banhistas pendurarem as suas roupas. A água salgada vinha por umas torneiras e era arrefecida com água doce. No piso superior existia um grande terraço onde as pessoas podiam tomar banhos de sol. Este estabelecimento tinha dois ou três funcionários a fim de efectuar a sua manutenção diária." (CAMPOS, 2010: 10).

De acordo com Lopes (1985), este edifício foi provavelmente construído nos finais do séc. XIX, princípios do séc. XX. Os banhos quentes eram uma atração que trazia anualmente a Sines cerca de uma centena de visitantes, após a conclusão do ciclo agrícola. Em 1941, Sines foi alvo de um terrível ciclone que destruiu por completo o estabelecimento de banhos quentes assim como todos os edifícios em seu redor.

A aldeia de Porto Covo teve igualmente uma infraestrutura similar, que ainda se encontra em bom estado de conservação, embora tenha sido adaptada para outros fins e tenha cessado a sua actividade na década de 80 do séc. XX.

Por conseguinte, o passado evidencia que o Município de Sines reúne as condições naturais para o desenvolvimento de Centros de Talassoterapia, pois embora numa versão algo tosca, esta foi uma realidade que durante largas décadas atraiu turistas a Sines, que permaneciam durante vários dias, os da 
duração do tratamento e que, consequentemente, consumiriam a restante oferta, gerando dinâmicas turísticas. Parrinha (1998) descreve o método dos banhos salinos quentes realizados nestas estâncias, sobretudo no mês de Agosto e de Setembro, quando terminava o ano agrícola e os habitantes da região se deslocavam a estas estações balneares para tratarem as doenças de ossos, em banheiras com cerca de 200 litros de água do mar aquecida, com uma temperatura entre os $37^{\circ}$ e $39^{\circ}$, consoante os sintomas dos doentes. A época dos tratamentos, para além de respeitar o calendário agrícola, coincidia também com a conclusão do ciclo de vida das algas, quando o mar as arranca e as deposita nas praias, sendo os seus constituintes dissolvidos na água, após a sua degradação por ação dos agentes bioclimáticos.

Em suma, sobre este produto interessa salientar que esta unidade territorial tem a génese da sua atividade turística intimamente relacionada com os produtos de Turismo de Saúde e de Turismo de Bem-estar e que, embora no presente, seja inexistente, podem ser recuperados uma vez que a "matéria-prima" continua a ser uma constante, ainda que desaproveitada.

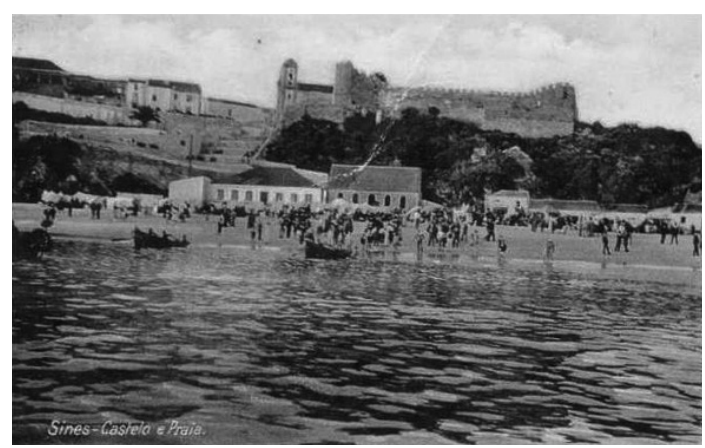

Figura 3

Banhos Quentes, Praia de Sines, 1940

Fonte: Autor desconhecido. Arquivo particular de Cármen Batalha

\section{Do diagnóstico à ação - as políticas e práticas para a produtização}

O desenvolvimento do Turismo de Saúde e Bem-estar, aliado aos recursos marinhos, prevê o concurso de um conjunto de fatores relacionados com o sistema turístico. Perante este pressuposto, nem todos os territórios reúnem as condições necessárias para apostarem nesta oferta de forma a serem competitivos no actual contexto de globalização. Trata-se de produtos híbridos, cuja afirmação depende da atratividade turística do destino, mas sobretudo da relação preço/qualidade dos serviços de saúde e bem-estar que the estão associados, e do contexto patrimonial em que se integram.
Neste momento, o Município de Sines não tem uma oferta ligada a este produto, ainda que possua as condições naturais para o efeito. Face ao exposto, poderemos concluir que o desenvolvimento e a afirmação destes produtos turísticos terá que passar pela criação da própria oferta, seguindo um modelo implementado por um número considerável de países que se libertou das exclusivas e tradicionais curas/ tratamentos termais passando a oferecer crescentemente serviços orientados para a saúde e para a sua prevenção, para o bem-estar físico e para a beleza. Ainda assim, segundo Cooper et al. (1995), os SPAs historicamente mais ligados às qualidades medicinais das suas águas, são os que têm tido mais sucesso neste processo de modernização termal. Esta situação alerta, eventualmente, para a necessidade de alcançar um equilíbrio entre uma oferta inovadora e a manutenção de alguns valores tradicionais, formatando a embalagem do produto sem no entanto adulterar o seu conteúdo. Na realidade, a maioria dos serviços no âmbito do Turismo de Saúde e de Bem-estar aliam a sofisticação do presente às técnicas do passado. Os tratamentos termais remontam aos romanos, a talassoterapia remonta à Grécia Antiga, e a origem das medicinas alternativas perde-se no tempo e no espaço.

As águas salinas de Sines e as técnicas utilizadas, a acreditar nos testemunhos orais e em alguns registos, eram altamente eficazes e atraíam visitantes de todo o país, pelo que há que começar pelo estudo científico das propriedades bioquímicas das suas águas salinas, e pelo conhecimento profundo dos processos ancestrais, fazendo posteriormente coexistir o passado com as exigências de sofisticação do presente.

Com a análise SWOT constante no Quadro II, realizada ao Município de Sines na perspetiva do Turismo de Saúde e Bem-Estar, parte integrante de uma análise mais global que traduz uma lógica de complementaridade entre este produto e outros igualmente considerados estratégicos para este território, evidenciam-se os catalisadores e os obstáculos ao seu desenvolvimento e consolidação, para que o exercício de planeamento possa definir objetivos, políticas, estratégia e práticas coerentes com o cenário de partida.

Após a realização do diagnóstico, que culmina na síntese constante no quadro anterior, estão reunidas as condições para avançar para uma proposta de produtização turística dos recursos ligados à saúde e ao bem-estar, numa abordagem que visa essencialmente uma rentabilização pouco convencional do mar, através da talassoterapia.

Nesse sentido definiram-se um conjunto de políticas e práticas, a partir da informação disponível e da informação recolhida através da realização de inquéritos por questionário e por entrevista, aos visitantes e aos stakeholders, respetivamente, e que se encontram resumidas no Quadro III. 
Quadro II

Análise SWOT do Município de Sines na perspetiva do Turismo de Saúde e Bem-Estar

\begin{tabular}{|c|c|c|c|}
\hline Pontos fortes & Pontos fracos & Oportunidades & Ameaças \\
\hline $\begin{array}{l}\text { - Antecedentes históricos } \\
\text { - Caraterísticas bioquími- } \\
\text { cas da água do mar e da } \\
\text { flora marítima } \\
\text { - Perdura da estância de } \\
\text { banhos quentes de Porto } \\
\text { Covo } \\
\text { - Consumo ao longo de } \\
\text { vários meses }\end{array}$ & $\begin{array}{l}\text { - Inexistência de infraes- } \\
\text { truturas e equipamentos de } \\
\text { qualidade } \\
\text { - Inexistência de hotéis que } \\
\text { integrem o serviço de SPA }\end{array}$ & $\begin{array}{l}\text { - Identificação do Turismo de Saúde e } \\
\text { Bem-Estar como produto estratégico } \\
\text { no âmbito do PENT } \\
\text { - Afirmação do cluster do Turismo de } \\
\text { Saúde e Bem-estar } \\
\text { - Valores da pós-modernidade, tra- } \\
\text { duzidos numa preocupação crescente } \\
\text { com a saúde e o bem-estar } \\
\text { - Procura crescente, a nível mundial, } \\
\text { deste produto turístico }\end{array}$ & $\begin{array}{l}\text { - Forte concorrência } \\
\text { - Inexistência de recursos hu- } \\
\text { manos com formação na área da } \\
\text { Saúde e Bem-estar } \\
\text { - Inexistência de entidades } \\
\text { formadoras que confiram perfis } \\
\text { especializados na área do Turis- } \\
\text { mo de Saúde e Bem-estar }\end{array}$ \\
\hline
\end{tabular}

Fonte: Elaboração própria com base nas entrevistas a um painel de stakeholders

Quadro III

Produtização do Turismo de Saúde e Bem-estar: objetivos, estratégias e práticas

\begin{tabular}{|c|c|}
\hline Objetivos & Estratégias e práticas \\
\hline $\begin{array}{l}\text { Recuperar a tradição do Município de Sines na } \\
\text { área da talassoterapia, afirmando esta unidade } \\
\text { territorial como destino turístico de Saúde e } \\
\text { de Bem-estar, na relação com o clima e com a } \\
\text { beleza paisagística. }\end{array}$ & $\begin{array}{l}\text { - Realizar um levantamento sobre a prática dos banhos quentes, com base em } \\
\text { testemunhos vivos e documentais. } \\
\text { - Inventariar os locais com apetência para o desenvolvimento de unidades de } \\
\text { Saúde e Bem-estar. }\end{array}$ \\
\hline $\begin{array}{l}\text { Fundamentar cientificamente a apetência desta } \\
\text { unidade territorial para os tratamentos de } \\
\text { talassoterapia. }\end{array}$ & $\begin{array}{l}\text { - Desenvolver uma linha de investigação no âmbito do Laboratório de Ciências } \\
\text { do Mar da Universidade de Évora (CIEMAR), localizado em Sines, direcionada } \\
\text { para o estudo do mar na perspetiva do Turismo de Saúde e o Turismo de Bem- } \\
\text {-estar. } \\
\text { - Realizar um estudo que avalie as características bioquímicas da água, fauna } \\
\text { e flora marítimas na perspectiva da talassoterapia e demais tratamentos de saú- } \\
\text { de e bem-estar. }\end{array}$ \\
\hline $\begin{array}{l}\text { Estimular, material e imaterialmente, a instala- } \\
\text { ção de novas unidades de saúde e bem-estar e de } \\
\text { SPA's nas unidades de alojamento já existentes, } \\
\text { em fase de projeto e em fase de construção }\end{array}$ & $\begin{array}{l}\text { - Recuperar a estância de banhos quentes do Porto Covo, a única subsistente, } \\
\text { transformando-a numa unidade moderna de talassoterapia. } \\
\text { - Conceber um sistema de incentivos, com o envolvimento do Turismo de Portu- } \\
\text { gal, para a instalação de unidades de Turismo de Saúde e de Bem-estar ao longo } \\
\text { da costa, mas com principal incidência na zona entre Porto Covo e o limite do } \\
\text { Concelho. }\end{array}$ \\
\hline
\end{tabular}

Fonte: Elaboração própria

Este produto turístico não se esgota nos tratamentos e nos programas disponibilizados aos turistas, existindo alguns elementos que permitem referir que a nova conceção de saúde e bem-estar e a sua associação ao tempo de descanso e de férias, reflete-se também ao nível do alojamento. $\mathrm{Na}$ hotelaria tradicional começou a ser prática corrente a oferta de serviços de manutenção física a par do serviço de alojamento, e nos estabelecimentos de categoria superior existe a tendência para a inclusão de serviços de estética e tratamento corporal, e mesmo para uma especialização na oferta de programas de manutenção implementados por profissionais qualificados. Paralelamente, existe uma oferta crescente de SPAs e resorts, estabelecimentos especializados na vertente de saúde e/ ou de bem-estar que asseguram, através de equipas de profissionais multidisciplinares (médicos e técnicos especializados em medicinas alternativas, talassoterapia, alimentação saudável, desporto), serviços integrados à medida das necessidades dos clientes (IQF, 2005). Trata-se de uma oferta paralela sobretudo direcionada para o bem-estar mas que começa a ter uma expressão significativa também em Portugal, sobretudo porque o acesso a estes serviços, um privilégio apenas de alguns pelos preços praticados, é actualmente uma moda carregada de simbolismo social.

Neste campo, o Município de Sines tem igualmente que desenvolver uma estratégia, nomeadamente através da articulação de parcerias, pois não possui unidades hoteleiras nem estabelecimentos com as especificidades supra-referidas. No entanto, o caminho poderá passar por vias diferentes, nomeadamente a recuperação da infraestrutura do Porto Covo, e eventualmente a construção de outras, no respeito por um modelo de arquitetura sustentável, enquadrável nas restrições à construção neste território, e que seja integrada nos produtos oferecidos quer pelas unidades hoteleiras quer pelo número crescente de unidades de turismo rural. Aliás, existe no Município vizinho, o de Odemira, um eco parque (ZMAR), cujo modelo, não devendo ser copiado pois a proximidade geográfica a isso não aconselha, poderá ser uma fonte de inspiração para a estratégia a desenvolver no Município de Sines.

A identificação do Turismo de Saúde e Bem-estar como um dos produtos turísticos estratégicos para o Município, mais do que uma atitude prospetiva e uma postura pró-ativa, reflete um comportamento reativo aos sinais emanados da procura global e à perceção de que este território possui condições 
naturais para uma oferta diferenciada face à concorrência. Para além da reciclagem do conceito e do modelo de funcionamento das estâncias de banhos, no sentido da prestação de serviços de bem-estar em paralelo com os terapêuticos, o desenvolvimento no âmbito destes produtos turísticos pode igualmente assentar em unidades desenvolvidas para o efeito, associadas ou não a estabelecimentos hoteleiros, eventualmente a integrar em roteiros de saúde e/ou de bem-estar. Tanto no caso das estâncias, como das restantes unidades prestadoras de serviços de saúde e/ou bem-estar, consideramos fundamental uma articulação interorganizacional privada/privada e privada/pública, no sentido da criação de uma imagem consistente de Portugal enquanto destino de Turismo de Saúde e de Bem-estar. Trata-se de uma questão importante ao nível das estratégias de marketing, e fundamental em termos de competitividade num contexto povoado por inúmeros países já especializados neste tipo de oferta, caso se pretenda que o Turismo de Saúde e de Bem-estar constituam um dos produtos estratégicos para o desenvolvimento turístico desta unidade territorial.

\section{A procura: quem é o público-alvo?}

O Turismo de Saúde e Bem-Estar é um produto passível de ser consumido pela globalidade de visitantes que procuram os territórios. Pelas suas caraterísticas, pela vontade consciente ou inconsciente de reproduzir comportamentos, porque corresponde a anseios individuais e coletivos, atrai a generalidade dos visitantes, mesmo aqueles para os quais não constitui o principal motivo da visita. No entanto, na sequência da investigação realizada, definiram-se perfis tipo, constructos teóricos, modelos puros de que a realidade se aproxima mas com os quais raramente coincide. Neste contexto, e entre os vários perfis identificados no âmbito da investigação mais alargada e nos termos referidos no ponto dedicado aos procedimentos metodológicos, surge o perfil do "Saudável", um visitante que pode ser oriundo de vários pontos do país e da Europa, obcecado com a saúde e o bem-estar, pertencente a um estrato socioeconómico médio/elevado, de ambos os sexos, escolhe os destinos em função da especialização dos tratamentos, sendo atraído para o Município de Sines pelas características bioquímicas da água do mar e da flora marítima. Tende a permanecer pelo período coincidente com o plano de tratamento, alojado em hotel ou casa alugada, evidenciando grandes exigências quanto à qualidade dos serviços turísticos. É consumidor ocasional de alguns dos subprodutos do Turismo Costeiro e do Turismo Industrial.

Este modelo, construído a partir das evidências da realidade, nomeadamente dos perfis dos visitantes inquiridos por questionário, e da informação estatística disponível para a unidade territorial em análise, permite a definição do público-alvo, direccionando o comportamento da oferta, nomeadamente no que concerne às estratégias de comunicação e marketing, contribuindo para a eficiência do planea- mento, da acção e dos investimentos subsequentes, atendendo à multidimensionalidade da sustentabilidade no desenvolvimento turístico.

\section{Conclusão}

O Turismo de Saúde e Bem-estar surge como uma via para o desenvolvimento turístico sustentável no Município de Sines, mas numa lógica de complementaridade com os restantes produtos que este território tem para oferecer. Aliás, a multiplicidade de atividades e de recursos, turísticos e não turísticos, que o caraterizam, associados à sua dimensão vs a escala global da oferta e da procura, impelem-nos no sentido da defesa desta mesma complementaridade entre produtos turísticos, entre atividades e entre territórios. Apenas assente neste princípio é possível diferenciar os territórios e torná-los competitivos face à concorrência globalizada, sobretudo quando o contexto obriga à harmonização de setores aparentemente antagónicos, em que o sucesso de uns tende a comprometer o desenvolvimento de outros. Sines é um destes casos, a indústria, a pesca, a logística e o turismo, têm interesses distintos e nalguns casos opostos, podendo colidir na ausência de uma visão estratégica integrada de desenvolvimento

Por outro lado, e ainda que a génese de Sines, território turístico, remonte ao início do século $\mathrm{XX}$, o desenvolvimento desta atividade centrou-se continuadamente no produto Sol e Mar, na sua abordagem mais convencional, marcada por uma forte sazonalidade e pelos respectivos impactos negativos que esta tem nas gentes e no território. O Turismo de Saúde e Bem-estar, associado ao mar, potencia os seu $52 \mathrm{~km}$ de costa, permite a diversificação da oferta turística e, perante o perfil da oferta e as tendências de comportamento da procura, tenderá a contribuir para esbater a sazonalidade, aumentar o tempo de estada média dos visitantes e seus gastos médios, permitindo uma utilização mais equilibrada do território, um maior retorno para os investimentos e, caso seja enquadrado num modelo de desenvolvimento sustentável, uma maior qualidade de vida para as populações.

\section{Bibliografia}

ARDELL, D. B. (1986) - High level wellness. ( $2^{\text {nd }}$ ed. $)$, Berkeley, Ten Speed Press.

BORMAN, E. (2004) - "Health tourism. Where healthcare, ethics, and the state collide". British Medical Journal, 328, pp. 60-61.

CAMPOS, M. M. e SILVA, V. da (1985) - Monografia de Sines. $\left(1^{\text {a }}\right.$ Ed. $)$. Sines, Escola Primária $n^{\circ} 1$ de Sines.

COOPER, C. P.; FLETCHER, J.; NOBLE, A. e WESTLAKE, J. N. (1995) - "Changing tourism demand in Central Europe: 
the case of Romanian tourist SPAS". The Journal of Tourism Studies, 6 (2), pp. 30-44.

DGPM - DIREÇÃO GERAL DE POLÍTICAS DO MAR (2013) “Estratégia nacional para o mar 2013-2020”. http: // www.dgpm.mam.gov.pt/Pages/ENM.aspx, acesso em 25-06-2015

DUNN, H. L. (1959) - "High-level wellness for man and society”. American Journal of Public Health, 49 (6), pp. 786-792.

FREIXO, M. J. V (2009) - Metodologia científica - fundamentos, métodos e técnicas. Lisboa, Instituto Piaget.

IGNARRA, L. R. (2003) - Fundamentos do turismo. (2 ${ }^{\mathrm{a}}$ ed.). São Paulo, Pioneira Thomson Learning.

IQF- Instituto para a Qualidade na Formação (2005) - O turismo em Portugal, Lisboa, IQF.

LOPES, F. L. (1985) - Breve notícia de Sines, pátria de Vasco da Gama. Nota introdutória de João Madeira (2a ed.). Sines, Câmara Municipal de Sines.

MINISTÉRIO DA ECONOMIA E DO EMPREGO (2013) - "Plano estratégico nacional do turismo: horizonte 2013-2015”. http://www.turismodeportugal.pt/, acesso em 2006-2015.

MUELLER, H. e KAUFMANN, E.L. (2001) - "Wellness tourism: market analysis of a special health tourism segment and implications for the hotel industry". Journal of Vacation Marketing, 7(1), pp. 5-17.

PARRINHA (2008) - "Banhos salinos quentes”. In: INFARMED(ed.) - Remédios do mar. Lisboa, INFARMED.

ROSS, K. (2001) - "Health tourism: an overview". HSMAI Marketing Review. http://www.hospitalitynet.org, acesso em 29/05/2015.

THR - ASESORES EN TURISMO HOTELERÍA Y RECREACIÓN, S.A. (2006) - Dez produtos estratégicos para o desenvolvimento do turismo em Portugal - saúde e bem-estar. Lisboa: Turismo de Portugal.

TRAVIS, J. W. (1984) - "The relationship of wellness education and holistic health". In GORDON, J. S. (ed.) - Mind, body and health. New York. Sciences Press, pp. 188198. 